\title{
Marketing regulations do not apply to individual clinicians
}

\author{
Stephen J W Evans professor of pharmacoepidemiology \\ Medical Statistics, London School of Hygiene and Tropical Medicine, London WC1E 7HT, UK
}

The "licensing" process generally works well to protect patients from drug companies that promote ineffective or unsafe products. ${ }^{1}$ This regulatory system is not intended to, and should not, regulate clinical practice. In the UK the General Medical Council has applied the industry regulation system to clinical practice, thus discouraging, if not essentially forbidding, clinicians from prescribing safe and effective products for which drug companies, for profit reasons, have not applied for marketing authorisation. Drug regulation does not, and should not, take cost into account.

The EU directive and the court case that the GMC cites to defend its guidance do not apply to individual pharmacies preparing products for individual patients' use and hence do not apply to individual clinicians. ${ }^{2}$ The GMC and its lawyers should review more carefully the EU law and understand the difference between "unlicensed" and "outside the marketing authorisation." They should not apply law targeted at companies to individual clinical practice. Then the National Institute for Health and Care Excellence (not bound in law to recommend products only for indications where there is a marketing authorisation) can make untrammelled decisions on cost effective products. Sadly, the drug industry continues to damage its public reputation by opposing this thinking. ${ }^{3}$

Competing interests: I am a European Commission appointed independent expert member of the pharmacovigilance and risk assessment committee at the European Medicines Agency which assesses safety of drugs and vaccines that are marketed in the EU.

1 Aronson JK, Ferner RE. A licence to cure. BMJ 2015;350:h1723. (1 April.) 2 Dickson N. The GMC's stance on Avastin. BMJ 2015;350:h2043.

3 Cohen D. Why have UK doctors been deterred from prescribing Avastin? BMJ 2015;350:h1654. (1 April.) 